\title{
THE GRAVITY REFERENCE RESPONSE, THE ROTATION SENSA- TION, AND OTHER ILLUSORY SENSATIONS EXPERIENCED IN AIRCRAFT AND SPACE FLIGHT*
}

\author{
G. L. SHILLINGER, JR**., R. J. VON BAUMGARTEN \\ Ames Research Center, NASA, Moffett Field, Calif. 94035, U.S.A. \\ and
}

Mental Health Research Institute, University of Michigan, Ann Arbor, Mich. 48104, U.S.A.

(Received 24 April, 1973)

\begin{abstract}
An analysis of the gravitational and inertial forces which act during aircraft flight upon the vestibular systems of the aircraft occupants reveals that in the absence of a visual horizon, certain illusory sensations are predictable for various acceleration environments. Horizontal forward applied acceleration results in a climbing (backward tilting) sensation; conversely, horizontal rearward applied acceleration results in a diving (forward tilting) sensation. During any attempt to achieve weightlessness in aircraft parabolic flight, special care has to be taken to avoid unintended longitudinal ( $x$-axis) accelerations. Recent flight tests established that the 'rotation sensation' (Dzendolet, 1971; Gerathewohl, 1956) during entry into parabolic flight can be attributed to the existence of unintended longitudinal accelerations. However, the 'inversion illusion' (Graybiel and Kellogg, 1966) felt by some human subjects at $0 \mathrm{~g}$ seems to be different from the rotation sensation and could be caused by the diminished pressure forces of the otoliths on the maculae. The 'inversion illusion' of man correlates well with the blind fish diving behavior observed during aircraft parabolic flight (von Baumgarten et al., 1969, 1972). It is suggested that the fish low $g$ diving response and the human inversion illusion are due to the substitution of a predominately shearing force of low magnitude as a vestibular reference in place of a normal, predominately pressure force. This hypothesis indicates that vestibular senses alone cannot provide meaningful postural orientation to simulated or actual gravity of a magnitude below that of Earth's gravity.
\end{abstract}

\section{Introduction}

The vestibular apparatus provides two kinds of information: angular acceleration, which is measured by the semicircular canal system, and the position of the head relative to the Earth's gravitational field, which is measured mainly by the otolith organs. Since linear accelerations of appreciable strength and weightlessness of longer duration than encountered in free fall rarely appeared in evolution, such stimuli did not have sufficient influence for survival to lead to the development of meaningful responses. The otoliths can be displaced by inertial reactive forces as well as by the Earth's gravity. The direction in which the otoliths are displaced by the Earth's gravity is dependent upon the position of the otoliths, or the position of the head, as related to Earth.

* This research was supported in part by NASA Contract NAS2-6057.

** G. L. Shillinger, Jr. is with the Flight Projects Development Division, Ames Research Center, NASA, Moffett Field, California.

₹ The present address of R. J. von Baumgarten is Dept. of Physiology, University of Mainz, West Germany. 
Recent experience with moving vehicles, especially those in aerospace flight, has shown that linear accelerations and the absence of the Earth's gravity stimulation can produce certain illusory sensations caused by the vestibular apparatus. Human space flight has proven that at least for periods up to several weeks, such vestibular responses can be tolerated and seem to be no serious threat to space flight. The long term adaptability of the human vestibular system is apparently sufficient to adjust reasonably well to the new weightless environment. However, experience in marine and aerospace travel has also shown that adaptability and susceptibility of man to unusual gravitoinertial situations vary greatly among individuals. It is in the best interest of applied problems of aerospace medicine as well as of basic science to explore the acting forces and the biological mechanisms which participate in the generation of vestibular illusory sensations and motion sickness.

In the following discourse an analysis is made of the gravitoinertial forces which are experienced in aerospace flight to explain some of the resulting sensations. The results of our previous work with blind fish are mentioned when it appears useful for a better understanding of the human vestibular functions in comparable gravitoinertial situations.

\section{Gravity Reference Response and Aircraft Occupants}

Jongkees and Groen (1946) described a phenomenon in which a human subject has the sensation of being tilted when horizontally accelerated. This subjective sensation was explained through an analysis of the forces acting on the otolith apparatus. Von Baumgarten et al. (1971) measured the angular positions of blinded experimental fish in response to horizontal accelerations applied with a car or a parallel swing. When comparing the fish results and human tilt sensations, the correlation between the fish and the humans is clearly apparent. Instead of feeling tilted backwards as its human counterpart would, the blinded experimental fish actively tilts forward in response to a forward applied horizontal acceleration. Thus the fish avoids the backward tilted sensation by actively tilting forward.

Graybiel (1952) and Clark (1968) described the 'oculogravic illusion' during which a fixed target in the visual field apparently moves up during forward acceleration and down during rearward acceleration. Von Baumgarten et al. (1973) recently observed a downward deflection of the eyes during forward acceleration and an upward deflection of the eyes during rearward acceleration. This observation leads to a corresponding shift of the retinal image of the target which would explain the illusion. The oculogravic illusion in this case appears to be another human correlate of the gravity reference response fish behavior.

The gravity reference response is the vestibular orientation to an acceleration other than the Earth's gravity, as if this acceleration were the Earth's gravity. If horizontal acceleration is applied to a fish tank containing blind fish or to a chair containing a blindfolded man, the fish or the man interpret as the Earth's gravity the resultant vector sum of the horizontal inertial reaction and the Earth's gravity. (The intertial 

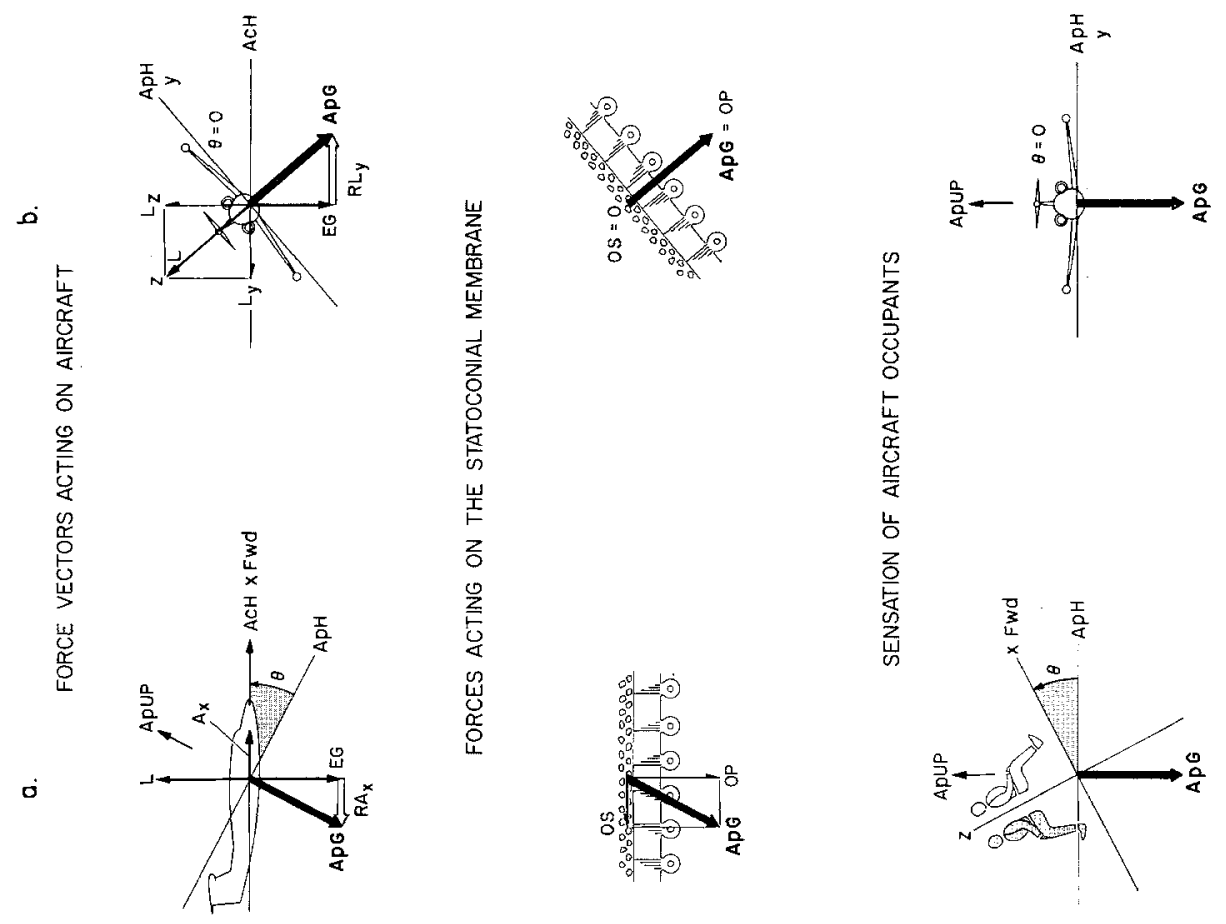

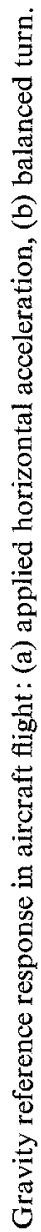

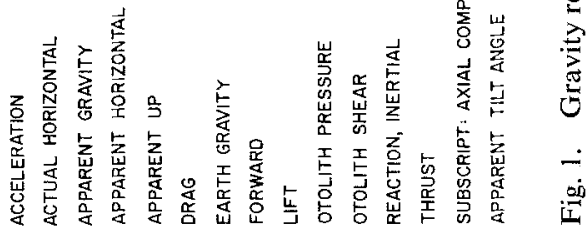

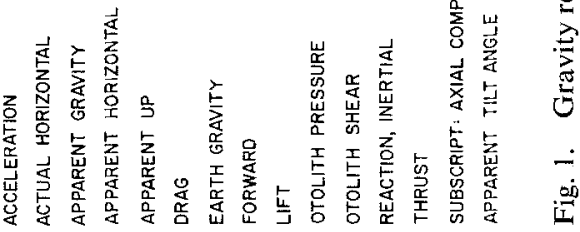

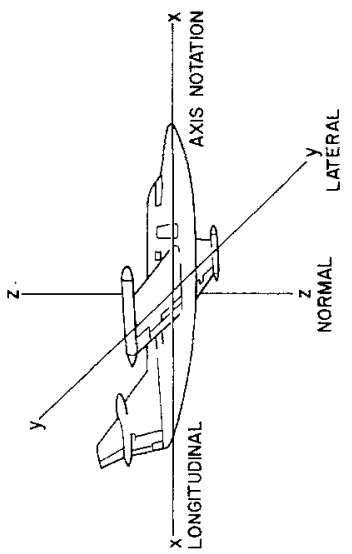

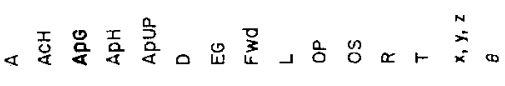


reaction is opposite in direction to the applied acceleration.) This resultant vector sum becomes 'apparent gravity'. Two examples of the gravity reference response related to aircraft flight are shown in Figure 1. In Figure la a horizontal acceleration is applied to the aircraft, for instance by increasing the engine thrust, and the apparent gravity vector is the vector sum of the inertial reaction to the applied horizontal acceleration and the Earth's gravity. The center illustration in Figure 1a depicts the forces acting on the statoconial membrane. The geometry of the utricular apparatus is complex and not arranged in a single horizontal plane as shown in the illustrations herein. However it is possible to simplify, as done, if only the vector forces on each part of the statoconial membrane are analyzed. In the bottom illustration the vestibular response of aircraft occupants is illustrated. The apparent gravity vector is pointed downward and the apparent horizontal is shown horizontally.

Note the sensed tilt angle. Aircraft occupants feel that they are tilted backward. Figure $1 \mathrm{~b}$ shows a balanced level turn. The horizontal component of aerodynamic lift pulls the aircraft inward. The inertial reaction to this applied acceleration and the Earth's gravity are vectorially summed to provide the apparent gravity vector. Although the gravity reference response sensation is that of being tilted laterally, the aircraft is also banked at an angle equal to this tilt. Thus the resulting vestibular angular response is compensated for by the aircraft attitude.

Of interest is the contrasting manner in which the gravity reference response affects the aircraft occupants in these two examples. With the applied horizontal acceleration in the direction of flight, the gravity reference response causes a deceptive illusion: that of being tilted rearward in the aircraft. On the other hand, in the banked level turn, the gravity reference response serves to align the aircraft occupants with the aircraft itself, thereby reducing the total sensation produced by the banked maneuver.

\section{Rotation Sensation During Straight Flight}

In Figure 2 straight level flight sequence is illustrated in which the aircraft occupants experience the vestibular sensation of being rotated forward in the aircraft. At point $2-1$, the aircraft is being accelerated forward as thrust is greater than drag. The aircraft occupants feel that they are tilted rearward in the aircraft as shown at the bottom. At point 2-2, thrust and drag are of equal magnitude and the aircraft occupants are vestibularly oriented to Earth gravity. With the final portion of the sequence point 2-3, drag is greater than thrust and the aircraft is accelerated rearward. As depicted, the aircraft occupants have the sensation of being tilted forward. Note that the aircraft occupants experience the illusory vestibular sensation of being rotated through a sizable arc although the aircraft attitude does not change.

In Figure 3 the aircraft is depicted in a nonvertical straight dive with a thrust-drag sequence the same as in Figure 2. However, at point 3-2, the magnitude of the apparent gravity is the same as the aircraft normal ( $z$-axis) component of the Earth's gravity. 

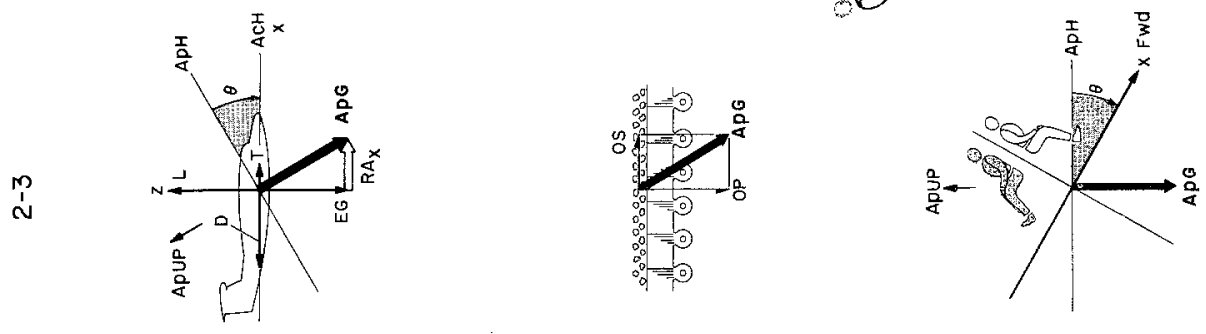

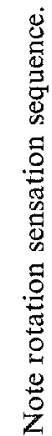
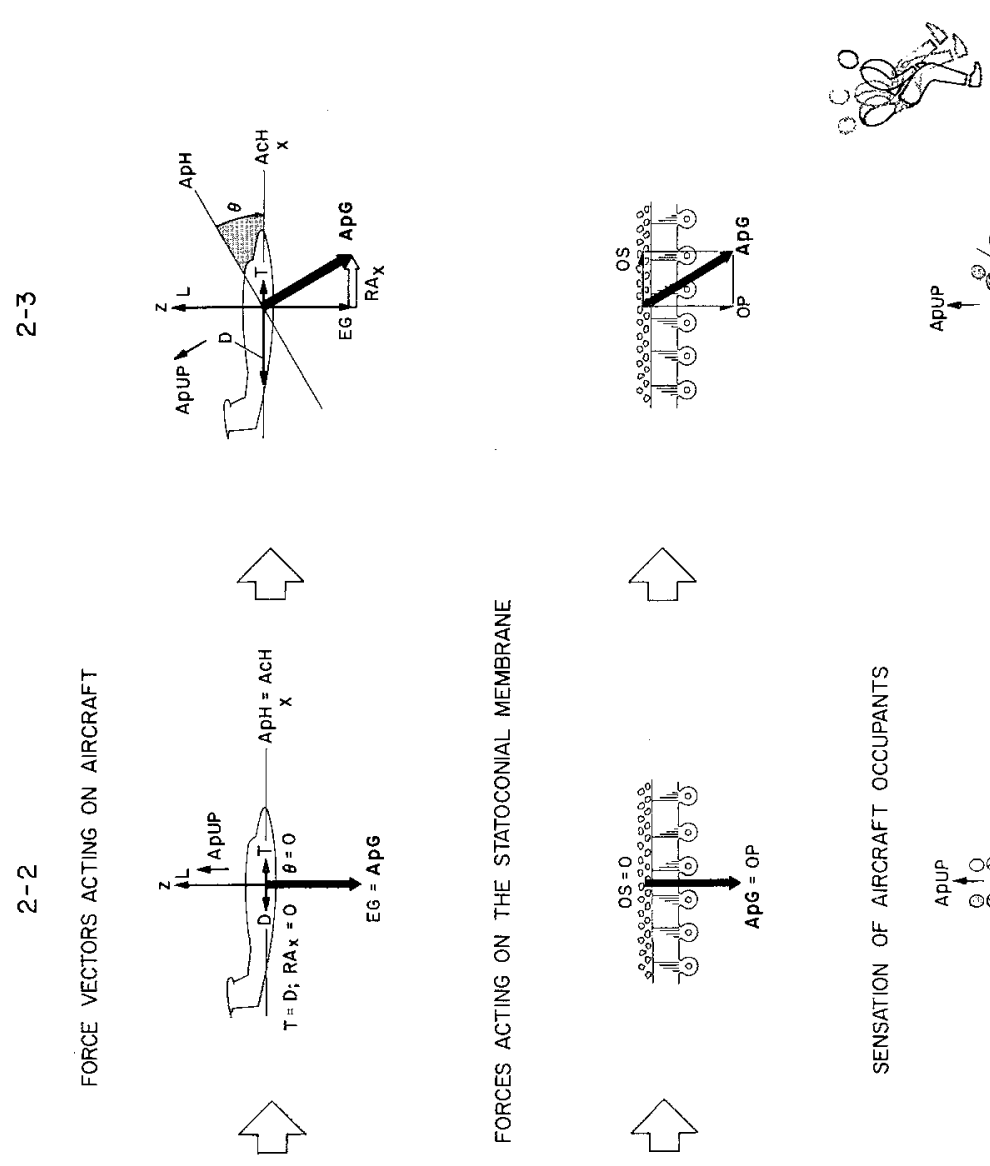

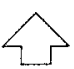

雚

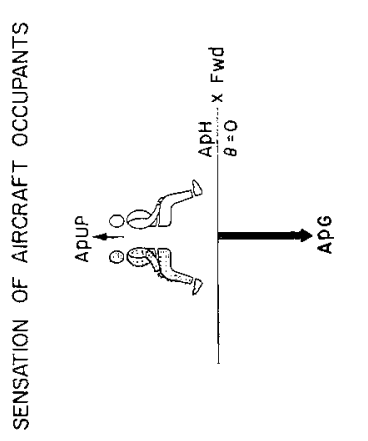

离

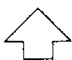
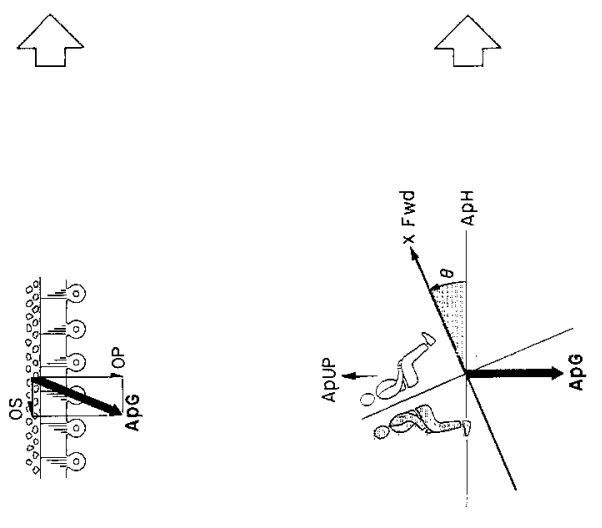

言 
$3-1$
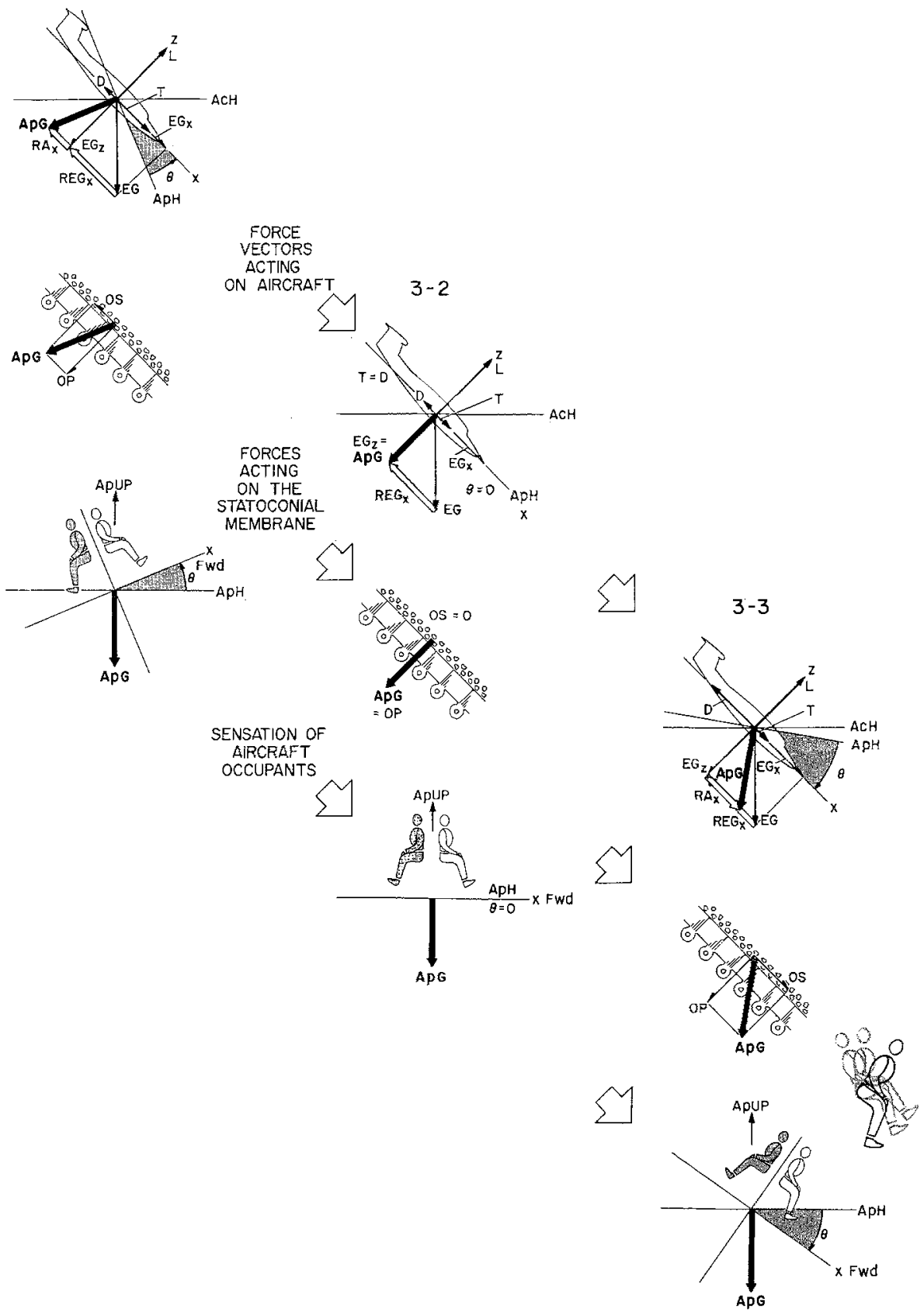

Fig. 3. Straight dive, where thrust initially exceeds drag but drag ultimately exceeds thrust. Note rotation sensation sequence. 


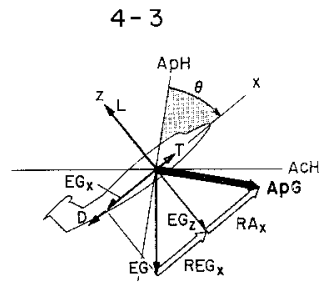

$4-2$

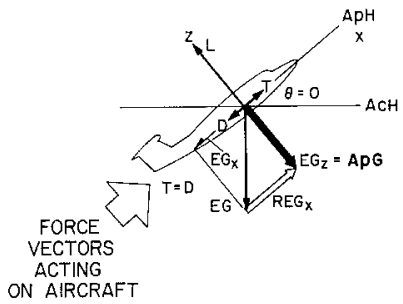

ON AIRCRAFT
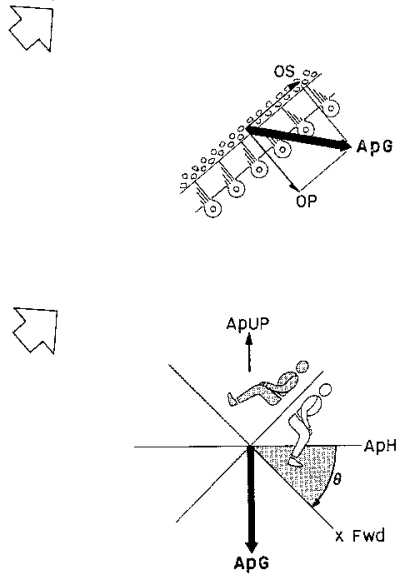
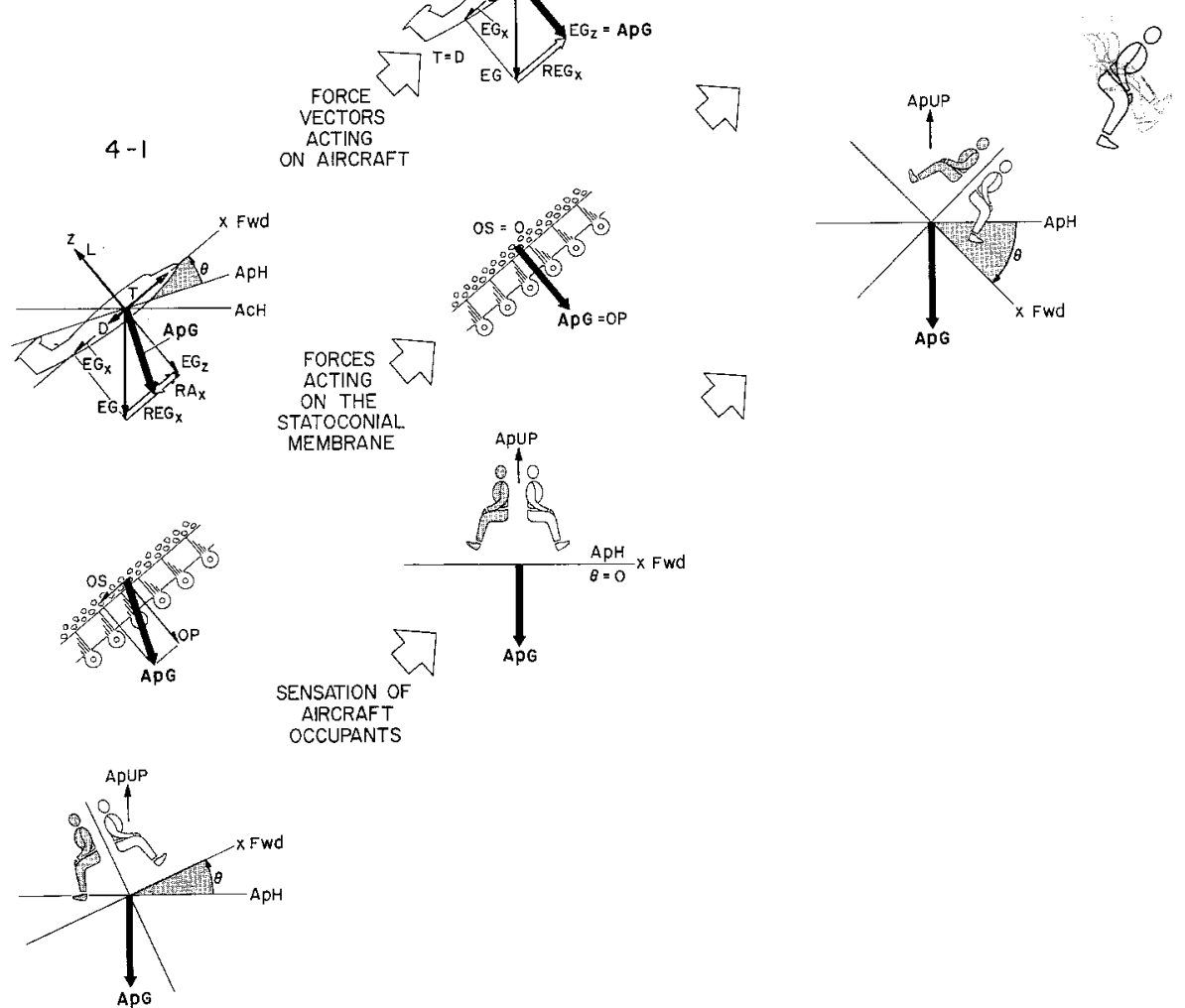

Fig. 4. Straight climb, where thrust initially exceeds drag but drag ultimately exceeds thrust. Note rotation sensation sequence similar to that of Figures 2 and 3.

Figure 4 shows the aircraft in a straight climb, also with a thrust-drag relationship sequence the same as that of Figures 2 and 3. The rotation sensation shown in Figure 4 is much the same as that of Figure 3, although the aircraft is in a climb instead of a dive. 

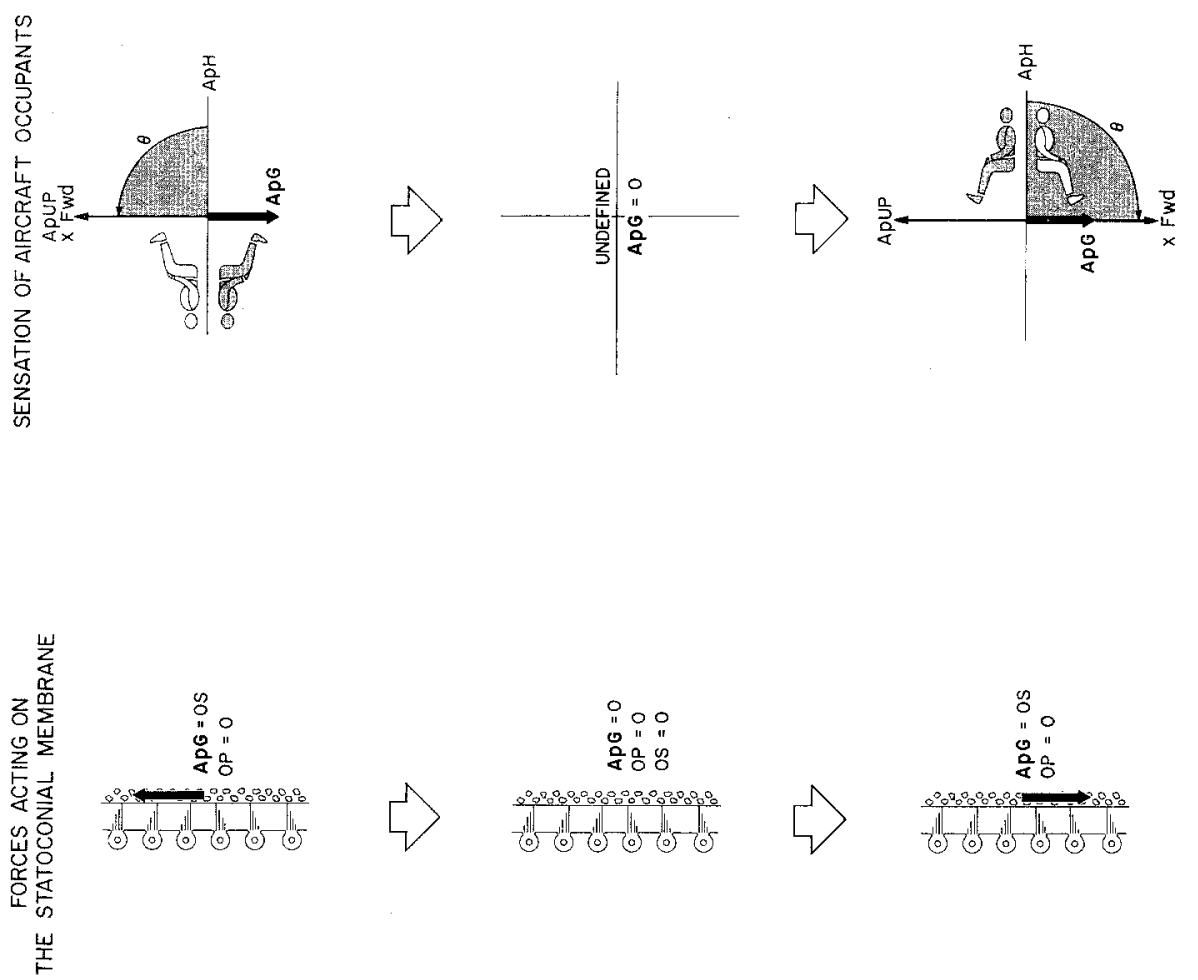

吾
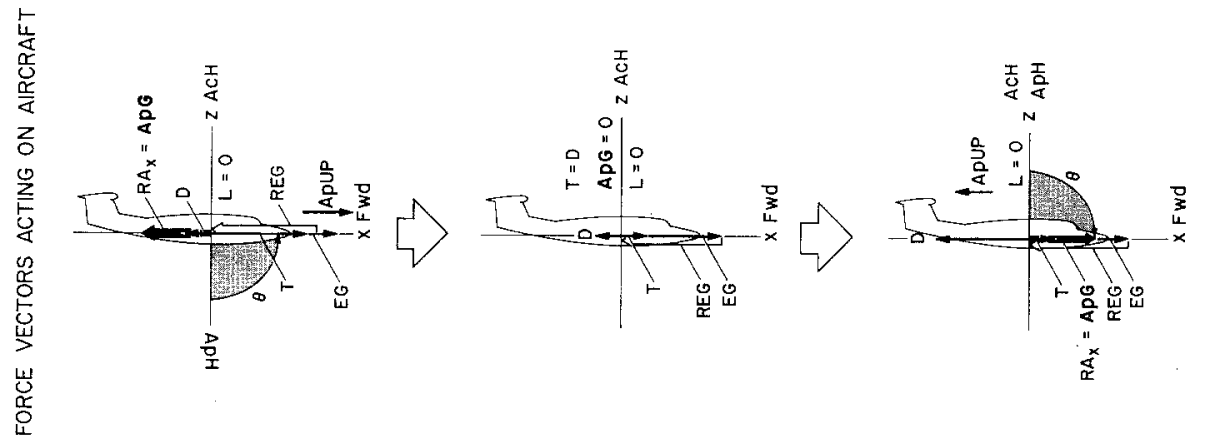

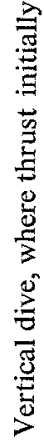

ì

$N$
1
1

$m$
1
$n$

in 


\section{Illusion of Direct Inversion}

In Figure 5 the aircraft is shown in a vertical dive. Initially, at point 5-1, the aircraft is being accelerated downward by the Earth's gravity and by the engine thrust which exceeds drag. The resultant inertial reaction of the aircraft in response to the Earth's gravity nullifies the Earth's gravity acceleration experienced within the aircraft. However, the reactive inertial acceleration caused by the thrust in excess of drag creates an apparent gravity which is directed upward. At point $5-2$, the thrust is nullified by the drag and a weightless condition results. At point 5-3, drag exceeds thrust and the apparent gravity is now directed downward. Thus the apparent gravity magnitude decreases from an upward direction (5-1) to zero (5-2), and then continues to increase in a downward direction (5-3). In this manner, an illusion of direct inversion without rotation is created as shown in the sequence of Figure 5.

Obviously the direct inversion sensation can be produced by other maneuvers where the apparent gravity changes direction, such as a pushover to an outside loop, continuing the pushover in a parabolic arc to a negative $G$-load on the aircraft, returning through $0 \mathrm{~g}$ to a positive $G$-load following the pushover past $0 \mathrm{~g}$ (normal or $z$-axis), or by yawing the aircraft from side-to-side during otherwise weightless flight (lateral or $y$-axis).

\section{Gravity Reference Response and Aircraft Parabolic Flight}

To explain illusory sensations experienced during aircraft flight intended to produce weightlessness, it is useful first to describe briefly how such flight is accomplished and some of the control requirements that accompany this method of producing weightlessness.

A general flight trajectory is illustrated in the upper portion of Figure 6. Point 6-1 shows the aircraft initially in level flight prior to commencing maneuvers leading to the weightless parabolic arc. At point 6-2, the aircraft has started a dive to acquire the high velocity prerequisite to establishing the high angular attitude with speed to fly the parabolic arc. At point 6-3, the aircraft is in a high $g$ pullup. At point $6-4$, the aircraft has reached the end of its pullup in a nose high attitude. Through point 6-5 the aircraft is pushing over to weightlessness. Point 6-6 represents the start of the weightless parabolic arc which ends at point 6-8. The aircraft follows an initially ascending path to an apex, point 6-7, halfway along the parabolic are and then descends to an altitude approximately equal to the altitude at which the aircraft started the parabolic arc. At point 6-8, the aircraft has re-acquired the speed with which the parabolic arc was started, and pulls out to level flight or the start of a subsequent maneuver. Point 6-9 shows the aircraft during the pullout maneuver.

During the period of simulated weightlessness, the aircraft is flown through a path which matches the trajectory of a free-falling object (without aerodynamic drag and having the same initial velocity as the aircraft). In this manner the acceleration field (apparent gravity) felt aboard the aircraft is held at zero as the Earth's gravity ac- 

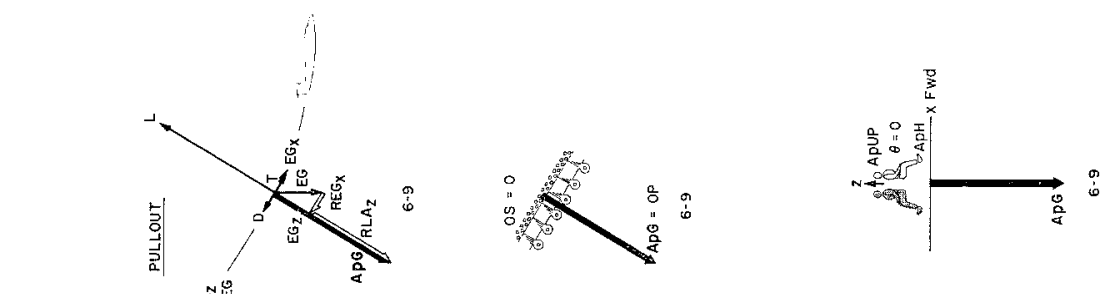

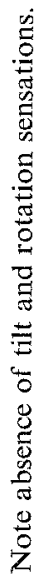
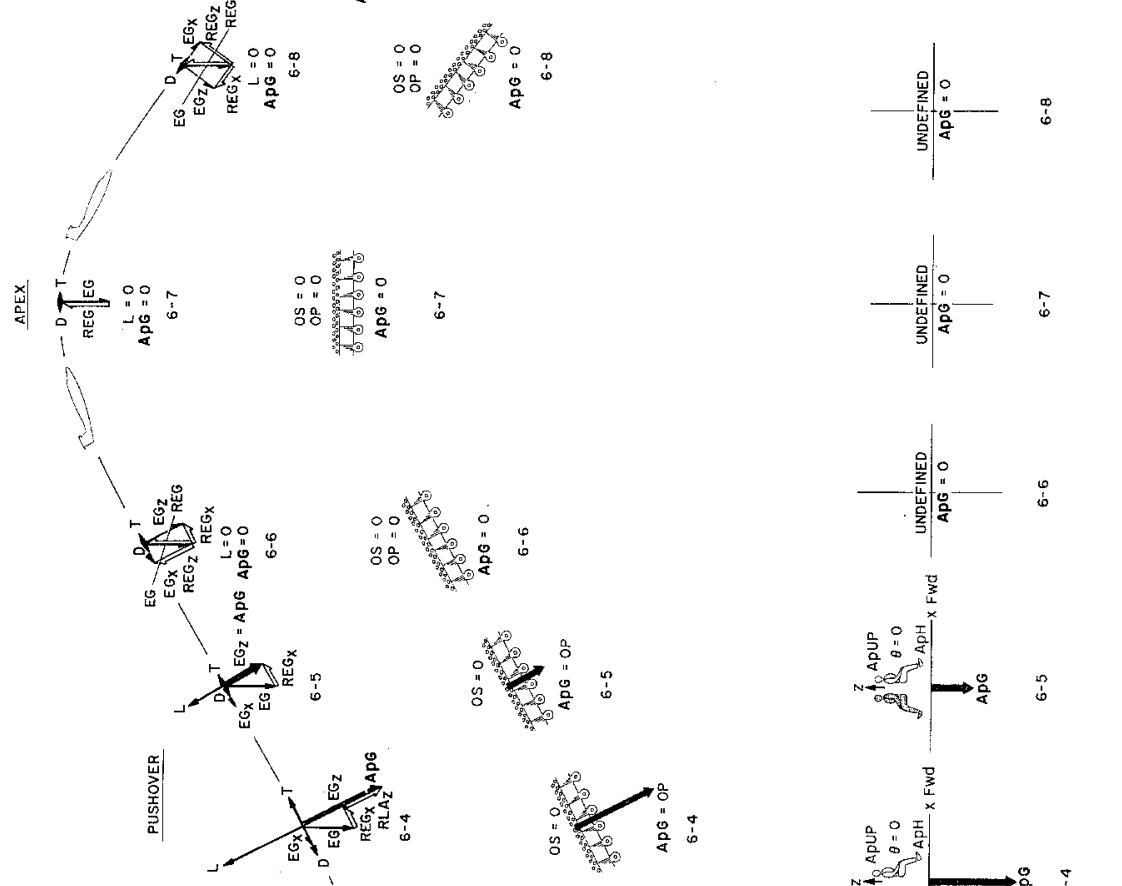

六
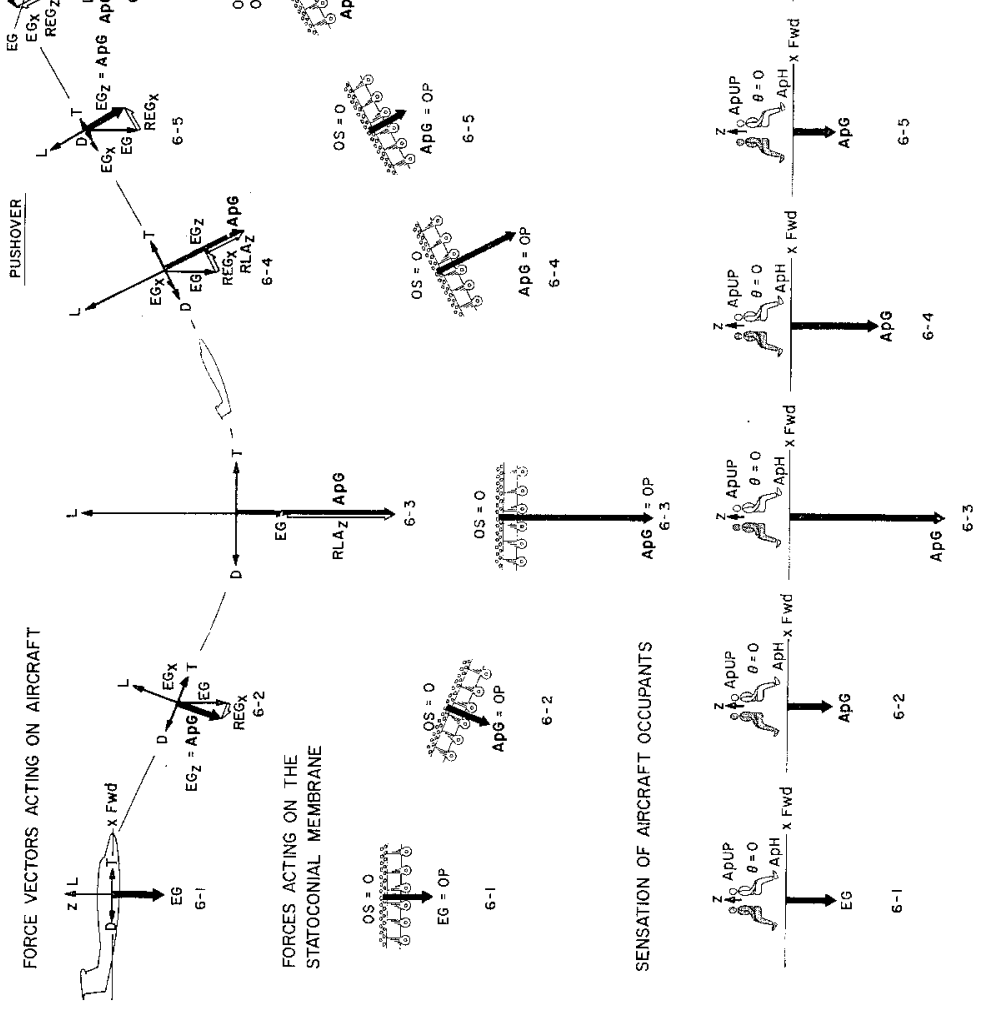
celeration vector is nullified by the reactive inertial acceleration produced by the movement of the aircraft.

To achieve true weightlessness, acceleration corrections are applied in three components. The pilot, through reference to a $z$-axis acceleration indicator, maintains the normal ( $z$-axis) acceleration at zero while the co-pilot, through reference to an $x$-axis acceleration indicator, maintains the longitudinal ( $x$-axis) acceleration at zero. The pilot, through use of the aircraft elevator control, attempts to maintain the aircraft aerodynamic lift force at zero throughout the parabolic arc. The co-pilot controls the longitudinal, $x$-axis, acceleration by maintaining engine thrust equal to aerodynamic drag through modulation of the engine power. Lateral, $y$-axis, acceleration is held at zero by the aircraft yaw damper or by manually maintaining balanced flight. To summarize, with this procedure the airplane is in essence converted from a flying machine to a near-ideal free-falling object. The pilot eliminates aerodynamic lift with the elevator control while the co-pilot cancels out aerodynamic drag by keeping engine thrust equal to aerodynamic drag.

In the sequence of sensations depicted in Figure 6, note that there is no tilt or resulting rotation sensation shown. With the exception of the parabolic arc, where orientation is undefined, the apparent horizontal is always aligned to the longitudinaltransverse $(x-y)$ plane of the aircraft. Thus, the aircraft occupants have the sensation of being level within the aircraft although their weight, i.e., the apparent gravity magnitude, undergoes considerable change, ranging from zero to three times its normal value. There is one important assumption underlying the sequence of maneuvers which produce weightlessness depicted in Figure 6. Throughout the sequence, the engine thrust magnitude must be equal to aerodynamic drag.

To develop this analysis, it is useful at this point to review the forces or accelerations involved and how each affects the acceleration field aboard the aircraft.

First consider the Earth's gravity. The pull of the Earth's gravity causes the aircraft to fall toward the center of Earth with an acceleration equal to $1 \mathrm{~g}$. (Note that an aircraft fiying a parabolic arc does not start moving closer to Earth until after the upward velocity component has decelerated to zero at the apex of the parabolic arc.) This acceleration in turn creates an equal and opposite inertial reactive acceleration which influences the acceleration (apparent gravitational) field aboard the aircraft. The inertial reactive acceleration caused by the Earth's gravity cancels out the Earth's gravity itself in the acceleration field experienced by the aircraft occupants.

Next to be considered is aerodynamic lift. This force is directed upward along the normal ( $z$-axis) of the aircraft. Aerodynamic lift opposes the normal ( $z$-axis) component of the Earth's gravity. The application of large positive aerodynamic lift will cause an inertial reaction acceleration downward along the normal (z-axis). Thus aerodynamic lift in itself serves as a gravitational substitute relative to the aircraft.

Another force to be considered is aerodynamic drag which is directed rearward along the aircraft longitudinal ( $x$-axis) and bears some relationships to aerodynamic 
lift. Generally, when aerodynamic lift is high, aerodynamic drag is also high. Conversely, when aerodynamic lift is zero, aerodynamic drag will most likely be at its minimum value (but not zero in a moving aircraft). The magnitudes of both aerodynamic lift and aerodynamic drag vary as the square of the relative wind speed.

Engine thrust, another force, opposes aerodynamic drag and tends to pull the aircraft forward through the air. Jet engine thrust varies directly with the speed of the aircraft (assuming a constant throttle setting).

Several force or acceleration interrelationships are important in obtaining weightlessness with an aircraft.

First, the aerodynamic drag varies about the same as the aerodynamic lift. In the pushover to weightlessness, the aerodynamic lift is decreased so that the $G$-load in the $z$-axis is reduced from approximately $3 g$ to zero. During this transition the magnitude of the aerodynamic drag force is also reduced. Thus if the engine thrust is not similarly reduced with the throttle control, the thrust will most likely increasingly exceed the aerodynamic drag as the pilot brings the aerodynamic lift toward zero. In this manner a net forward longitudinal ( $x$-axis) acceleration would be applied to the aircraft.

In the ideal parabolic arc the aircraft speed through the air varies. The aircraft is at its maximum longitudinal speed at the beginning and at the end of the parabolic arc. At the apex or midpoint of the parabolic arc, the aircraft is at its minimum air speed. Due to the change in air speed, the pilot probably has to make minor corrections to the aircraft angle of attack throughout the duration of the parabolic arc. The change in the air speed affects aerodynamic drag and engine thrust in different manners. As previously stated, aerodynamic drag varies as the square of the aircraft speed while jet engine thrust varies directly with the aircraft speed. For instance, if the air speed at the beginning or end of the parabolic arc is twice the minimum air speed at the apex of the arc, then the thrust at the apex of the arc would be half that at the beginning or end of the arc. At the same time, the drag at the apex of the arc would be only one-quarter of the drag at the beginning or end of the arc. Therefore, in this example, if the thrust and drag were equal at the beginning or end of the parabolic arc without throttle modulation, the thrust would be twice the drag at the apex or midpoint of the arc. There are other conditions which affect the thrust and drag relationship, such as the change in air density during the parabolic arc, but the change in aircraft flight speed is the predominant influence. The co-pilot must continually reduce engine thrust by retarding the throttles during the ascending half of the parabola and then he must continually increase engine thrust by advancing the throttles during the descending half of the parabola if engine thrust is to be kept equal to aerodynamic drag.

In the pullout or exit from the parabolic arc, the co-pilot must advance the throttles in order to maintain engine thrust equal to aerodynamic drag, as the aerodynamic drag will increase with the application of increased aerodynamic lift. This allows $x$-axis weightlessness to be maintained immediately following the parabolic arc.

The requirement for engine thrust adjustment with the throttle control has been 
previously mentioned (Carlile, 1961; Garland, 1961; Useller et al., 1965; Weiss, 1962). It appears that in the initial attempts to achieve aircraft weightless flight, particularly with one pilot alone executing the maneuver, the normal manner of entering weightlessness was to push over until $0 \mathrm{~g}$ was indicated on the aircraft accelerometer ( $z$-axis) and then make throttle adjustments to eliminate the longitudinal ( $x$-axis) acceleration disturbance. Probably somewhat later it was determined that aircraft power must be reduced simultaneously with the movement of the aircraft elevator in order to nullify unbalanced longitudinal accelerations during the parabolic flight entry pushover and exit pullout maneuvers and during the parabolic arc itself.

\section{Effects of Thrust-Drag Imbalance Upon Weightlessness Simulation}

In the procedure reported by Gerathewohl (1956), it is evident that longitudinal ( $x$-axis) acceleration disturbances did exist and were experienced during the test flight trajectories. "The pilot flew the ascending arc of the parabola at full throttle, the descending part with about $75 \% \mathrm{rpm}$ in order to obtain weightlessness for about 25 to $30 \mathrm{~s}$." To eliminate longitudinal ( $x$-axis) accelerations, the pilot should have reduced power during the pushover in the parabola, adjusted the power during the arc itself and increased power during the pullout. No mention is made of any instrumentation or technique to eliminate longitudinal accelerations. The aircraft used was a two-seat T-33A. The pilot flew in the front seat while the experimental subject rode in the rear seat. There was no co-pilot.

Figures 7 and 8 illustrate the likely effects of the procedure quoted above. Normal, $z$-axis, weightlessness is assumed throughout the parabolic arcs. In Figure 7 it is assumed that thrust exceeds drag throughout the parabolic arc. Figure 8 shows what may have occurred in the descending half of the parabolic arc when the engine rpm was reduced from 100 to $75 \%$. In Figure 8 it is assumed that this power reduction has caused the aerodynamic drag to exceed the engine thrust.

Note the $90^{\circ}$ rearward rotation sensation shown in the sequence 7-1 through 7-3. Throughout the parabolic arc shown in Figure 7 , the apparent gravity vector is aligned with the aircraft longitudinal axis ( $x$-axis) toward the aft end of the aircraft. In this case the gravity reference response corresponds to the sensation of being tilted $90^{\circ}$ rearward in the aircraft.

During pushover, 7-1 through 7-3, the aircraft occupants experience the sensation of being rotated rearward while the aircraft is pitching forward. Similarly, counter to the movement of the aircraft, the occupants experience the sensation of being rotated forward while the aircraft is pitching rearward during the pullout, 7.5 through 7-7.

In Figure 8 the apparent gravity direction is reversed from aft to forward in the longitudinal axis ( $x$-axis) of the aircraft at the apex of the parabolic arc. In the sequence 8-1 through 8-3, a direct inversion sensation is depicted. During the pullout, 8-4 through 8-6, the aircraft occupants experience a rearward rotation sensation prior to the restoration of a level sensation within the aircraft. 


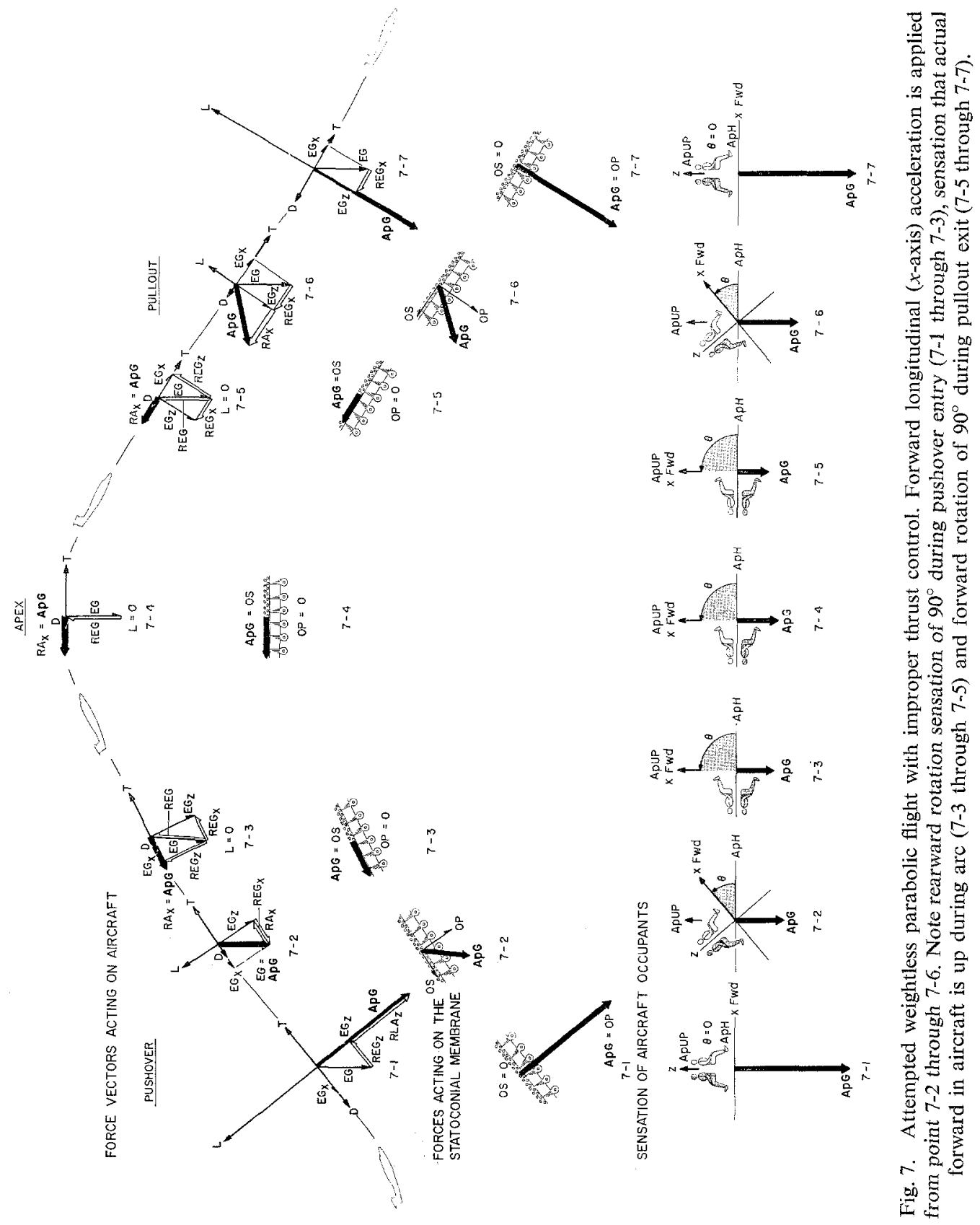




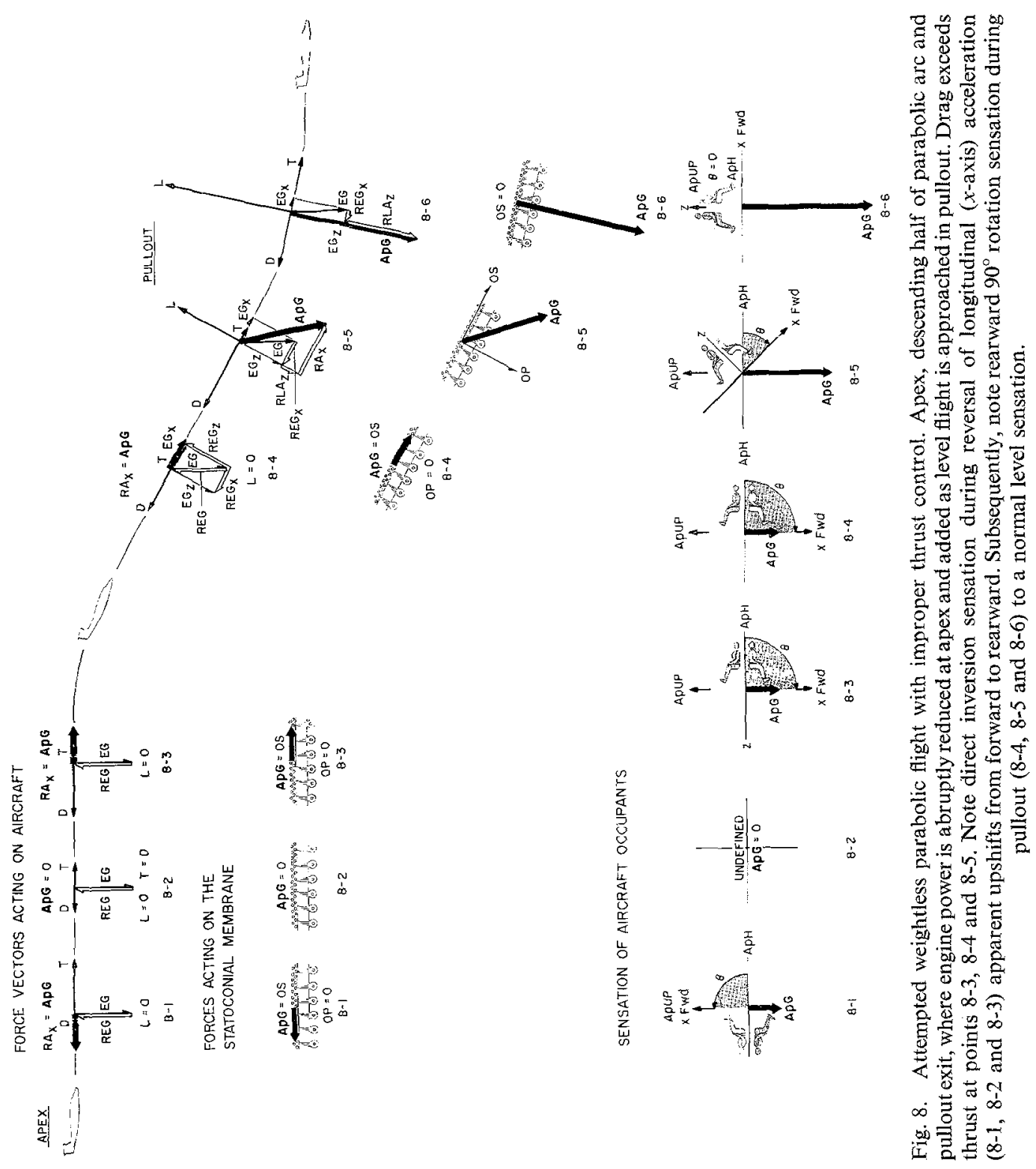


The aircraft pilot procedures of Gerathewohl's (1956) work, as previously stated, would produce a longitudinal ( $x$-axis) acceleration environment within the aircraft, with the apparent gravity vector directed rearward during the ascending half of the parabolic arc. Parabolas were recently flown with a Learjet 23 using procedures identical to those of Gerathewohl's (1956) work, i.e., $100 \% \mathrm{rpm}$ in the ascending half of the parabolic are and a thrust reduction to $75 \% \mathrm{rpm}$ at the apex and during the descending half of the parabolic arc. This procedure produced a longitudinal acceleration environment aboard the aircraft in which the inertial reaction vector (apparent gravity) was directed aft during the ascending half of the parabolic arc and forward when, or sometime after, the power was reduced to $75 \% \mathrm{rpm}$ at the apex of the parabola. Using this procedure for eight parabolic flight maneuvers resulted in an average of $0.18 \mathrm{~g} x$-axis acceleration magnitude upon completion of the pushover to $0 \mathrm{~g}$ normal, or $z$-axis, acceleration. The $x$-axis longitudinal acceleration increased slowly and smoothly to a peak value of $0.20 \mathrm{~g}$ at the apex. After the power had been reduced the $x$-axis acceleration was initially $-0.01 \mathrm{~g}$ and steadily

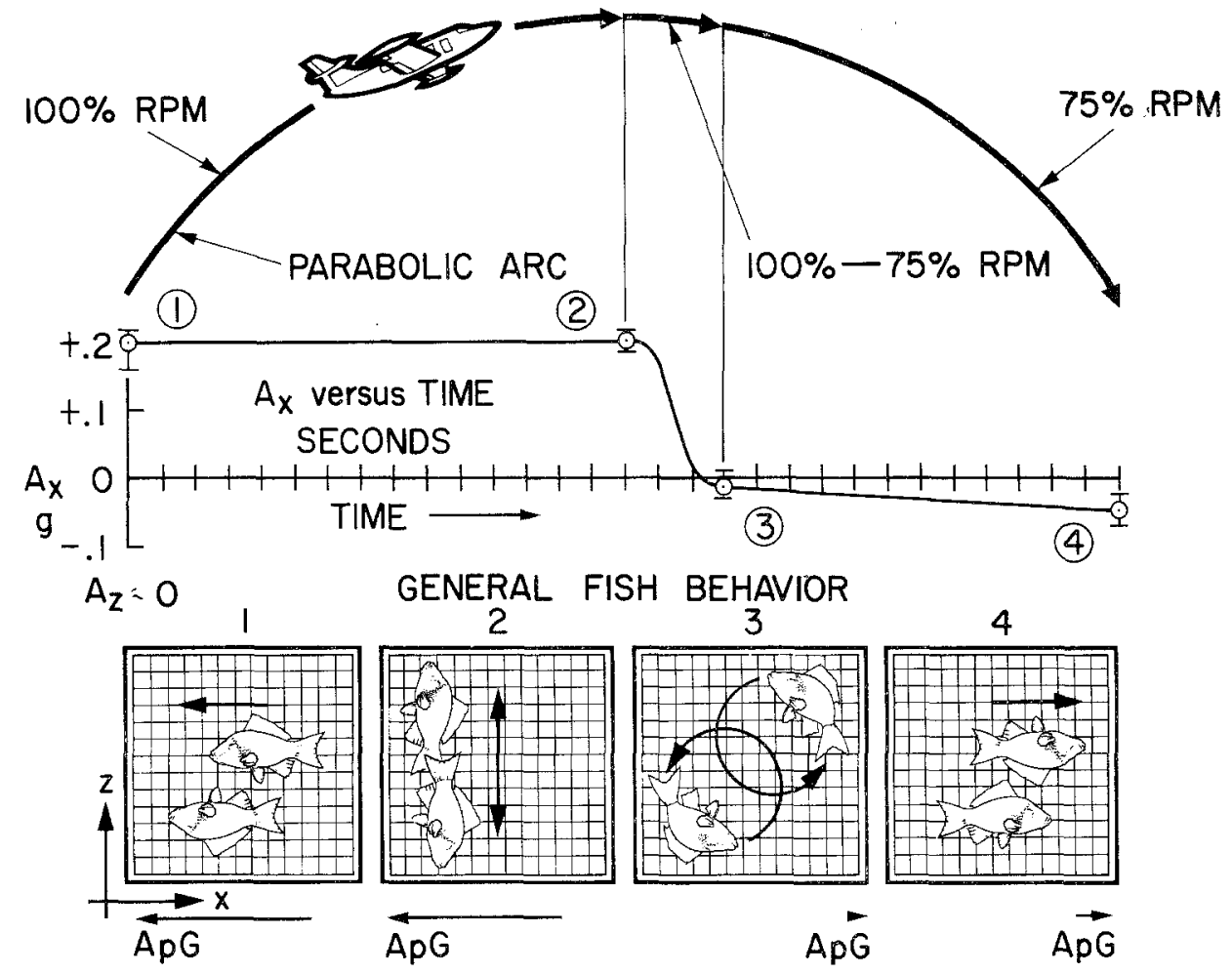

Fig. 9. Longitudinal accelerations acting on Learjet 23 aircraft in parabolic arc where power is maintained at $100 \% \mathrm{rpm}$ to apex and then reduced to $75 \% \mathrm{rpm}$. Blinded fish behavioral responses are shown. Normal acceleration is assumed to be zero. 
decreased to $-0.04 \mathrm{~g}$ at the start of the pullout. Longitudinal acceleration is plotted against time in Figure 9.

Since the Learjet 23 type aircraft has approximately the same performance characteristics at the Lockheed T-33A, the longitudinal accelerations described above should closely resemble those which acted upon the human test subjects in the parabolas of the Gerathewohl (1956) work.

During these recent eight parabolic flight maneuvers the behavioral responses of two blind goldfish were photographed. An experimental set-up similar to that described by von Baumgarten et al. (1972) was used. The general response pattern of the fish is shown in Figure 9. This response pattern assumes the absence of normal (z-axis) acceleration disturbances, particularly during the descending half of the parabolic arc when the longitudinal ( $x$-axis) acceleration was low. Diving responses toward the rear wall of the fish tank occurred consistently early in the parabolic arc. The fish subsequently continued diving toward the rear tank wall or used it as an apparent bottom level horizontal touch cue and swam parallel to this upright surface. After the aircraft power was reduced at the parabola apex and the longitudinal $x$-axis acceleration decreased, fish behavior was not as consistent as it was during the ascending half of the parabolic arc. The fish generally moved away from the rear wall and, toward the end of the parabola, dove toward the forward wall of the fish tank, apparently in response to the new apparent gravity direction and value. In many cases, the fish looped or dove at the tank bottom or top in response to normal ( $z$-axis) accelerations. In half the cases, the fish maintained orientation to the rear fish tank wall either temporarily or during the complete descending half of the parabolic arc. Often the normal ( $z$-axis) acceleration magnitude exceeded that of the longitudinal ( $x$-axis) acceleration during the descending half of the parabolic arc. This condition may have been caused by the low longitudinal acceleration magnitude during the descending half of the parabolic arc and the requirement for augmented aircraft attitude adjustment due to the thrust (and airspeed) reduction at the parabola's apex. With accelerations in all axes below the diving response threshold value and without touch cues, the fish responded by looping.

A passage from Gerathewohl's (1956) work describing the rotation sensation by a test subject is quoted below. The reported sensation correlates well with the apparent rotation depicted in sequence 7-1 through 7-3 and with the responses of the fish described above.

"The most remarkable sensation was one of having begun a 'back-flip' and becoming suspended with the back horizontal, face upward. I have done a fair amount of tumbling on gymnastic teams in high school and college. The sensation in flight was one of having started a 'back-flip' from a standing position and then becoming 'hung-up' part way over - looking toward the sky but not completing the flip. It was important to note that there was no continuous feeling of motion once this feeling of a partial backward tumble reached the inverted position.

There was no particular enjoyment nor dislike for the maneuver. Instead a feeling of indifference. No somatic sensations referable to viscera - such as sinking stomach, 
etc. Perhaps a longer flight with more runs would be indicated since there was no sensation of motion sickness from the few runs experienced.

The flight was taken without a hood enclosing the cockpit so that visual references outside were available. However, I found myself ignoring the outside environment not bothering to look for my orientation with reference to the ground."

Since the ascending half of the parabolic arc lasted about $15 \mathrm{~s}$ and the human test subject was acted upon by a longitudinal apparent gravitational vector directed aft during this entire time period, the sensation of being continuously suspended after a quarter-turn back flip is explained. In addition, the longitudinal acceleration magnitude during the descending half of the parabolic arc was apparently of a much lower magnitude than that of the ascending half. In fact, this longitudinal acceleration vector may not have been reduced to zero or reversed. Another complication is that during and immediately following the reduction of power at the parabola's apex, the aircraft pilot has a more difficult task of holding precise $0 \mathrm{~g}$ in the normal or $z$-axis, as some additional aircraft flight attitude adjustment is essential in order to maintain zero aerodynamic lift. These are all reasons why the human test subject may not have experienced and did not report any sensation beyond the continued sensation of being suspended following the sensed quarter-turn back flip. The predominant parameter to which this individual oriented, vestibularly and by touch cues, was the longitudinal apparent gravitational vector, which was of a magnitude of about $0.2 \mathrm{~g}$, was directed aft relative to the aircraft, and persisted for about $15 \mathrm{~s}$ during the ascending half of the parabolic arc.

\section{Responses to Low Apparent Gravitational and to Weightlessness Environments}

The problem remains as to whether apart from the initial rotation sensation caused by the gravity reference response, the low or $0 \mathrm{~g}$ environments can act as stimuli to the vestibular system and hence cause illusory sensations. While this problem has not been systematically studied, verbal reports about subjective sensations are available from Astronauts and Cosmonauts (Billingham, 1966), in addition to the updown' inversion illusion (Graybiel and Kellogg, 1966) experienced in aircraft parabolic flight. Because of the persistence of this sensation, it cannot be identical to and cannot have resulted from the initial rotation sensation as argued by Dzendolet (1971). Recently Berry (1972) reported episodes of 'tumbling sensations' of Astronauts in weightlessness. The oculoagravic illusion (Gerathewohl and Stallings, 1958; Clark, 1968) also seems to indicate a tilting illusion during hypogravity and weightlessness.

These observations about backward tilt and tumbling can be compared to animal experimentation with goldfish in aircraft parabolic flight (von Baumgarten et al., 1969, 1972). Blinded goldfish consistently displayed forward diving during hypogravity and a continuous forward looping (tumbling) motion during aircraft weightlessness. 
These fish experimental results appear to correlate very well with the reported illusions of men in comparable situations. The blinded fish are looping apparently in search of a 'down' direction for which they lack vestibular reference in the absence of any $G$-force. In spite of whatever position man would be in while experiencing the inversion illusion, he still would have the sensation of being inverted (Graybiel and Kellogg, 1966). Both the fish looping response and the man inversion illusion appear to be caused by an absence of an adequate acceleratory stimulus for the vestibular system. Instead of the sensation of rotation, it appears that the direct 'up-down' perception inversion illusion as reported by Graybiel and Kellogg (1966) correlates with the diving response displayed by fish.

The existence of the fish low $g$ diving response (von Baumgarten et al., 1969, 1972) makes it questionable whether or not the human vestibular sensation to low magnitude acceleration stimuli during weightlessness would actually be as depicted in Figures 5 through 8 . In these illustrations, only sensations attributable to the gravity reference response, not sensations correlatable to the diving response, are shown for all magnitudes of acceleration stimuli. Thus this work with blinded fish indicates that the vestibular apparatus is not capable of normal postural or head position orientation to low $g$. Additional human illusory sensations due to the effect of a $G$-force less than $1 \mathrm{~g}$ are very likely to occur but have not yet been sufficiently explored.

Another source of possible illusory sensations in weightlessness is the quantitative and qualitative misinterpretation of small (less than $1 \mathrm{~g}$ ) acceleratory stimuli as they occur during head movements and locomotion. It is a widely applicable rule of general receptor physiology that the sensation is a power function of the stimulus intensity (Weber-Fechner law). In the case of the otolith system, this relation would mean that the decrease of the strong background stimulus of the Earth's gravity would cause an increase in sensitivity to smaller inertial stimuli. Indeed, experiments with blinded fish in parabolic flight have shown that small acceleratory stimuli imposed on the background of $0 \mathrm{~g}$ had the remarkable effect of the fish immediately diving into the direction of the inertial reaction or apparent gravity. These responses were quantitatively stronger and different in direction than under normal $(1 \mathrm{~g}$, the Earth's gravity background) conditions. Despite the obvious caution necessary in applying results from experiments with fish to man, the observed fish behavior again helps us to understand better observations made by men in spaceflight weightlessness. It was reported by Berry (1969) that fast, intentionally produced head movements caused stomach awareness and motion sickness after a delay of a few minutes. Since it has been known for a long time that accumulation of stronger than normal vestibular stimuli as well as the strangeness and conflicting nature of such stimuli are prime factors of motion sickness (Money, 1970), these observations correlate very well with the experiments with fish. Although the man and fish physiologies and nervous systems are greatly dissimilar, the vestibular receptor mechanisms are homologous (Rand, 1950 ) and the study of fish behavior when subjected to various acceleratory stimuli is useful for improving our understanding of human sensations in these unique environments. 


\section{Receptor Mechanisms}

The question can be raised: What kinds of mechanical displacements of the otoliths occur during weightlessness as compared to normal conditions (i.e., $1 \mathrm{~g}$ environment)? This problem revives the longstanding and much disputed question of vestibular receptor physiology, i.e., whether the pressure or the shearing force of the otoligths is the physiological stimulus. With the head slightly tilted forward, the utricular macula would be about horizontal and the transition from $1 \mathrm{~g}$ to weightlessness would merely reduce the pressure of the otoconial membrane on the sense hairs of the utricular epithelium without much lateral dislocation. The observed diving response of an initially horizontal fish and the inversion illusion of an upright sitting man in aircraft parabolic flight seem to support to some degree the pressure hypothesis.

On the other hand, the diving and looping responses were also observed in fish which were caught at different nonhorizontal initial positions in the tank when the transition to weightlessness occurred. In these cases, the shearing force on the sense hairs must have decreased during the transition. In the sacculus epithelium of man, which is much more tilted in a normal head position than the utricular macula, diminishing shearing forces would occur also in the transition from normal $1 \mathrm{~g}$ conditions to weightlessness. From this argument as well as from other observations in the literature (Jongkees, 1950, 1968; Ogino et al., 1963; Yamagata, 1958), it appears likely that both changes of the shearing force and pressure changes perpendicular to the sensor epithelium can be sensed by the otolithic system. Von Békésy (1966) pointed out that shearing and pressure forces can always be seen as two components in a parallelogram
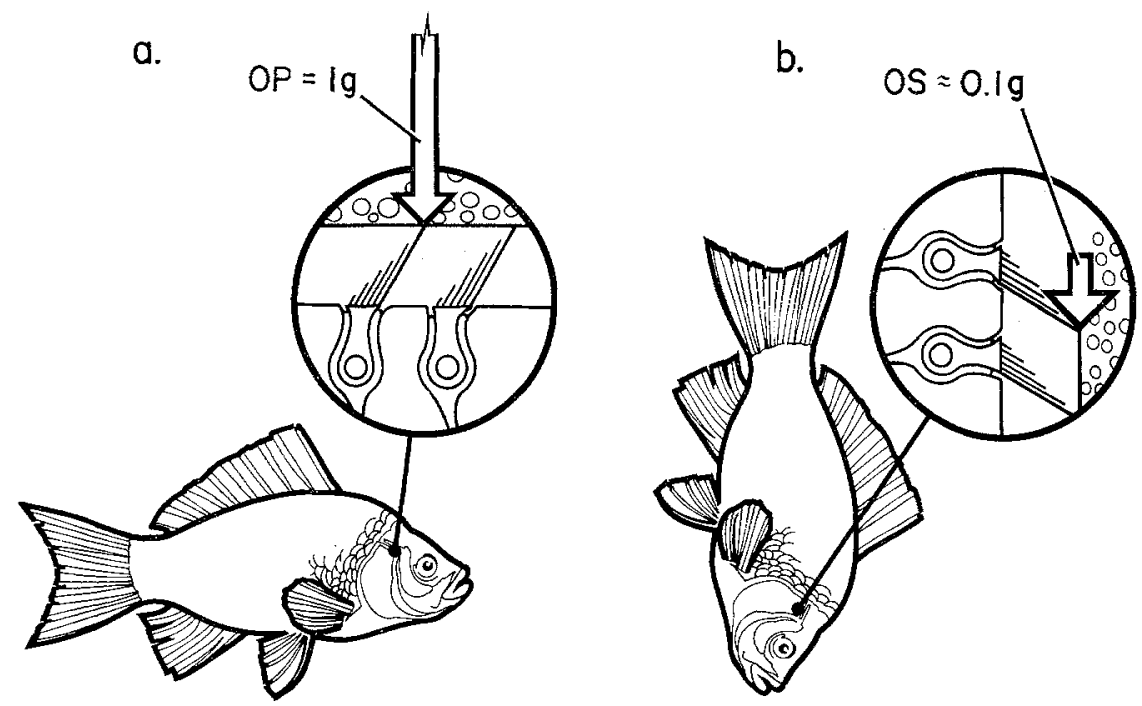

Fig. 10. Simplified schematic of possible receptor mechanism operation to explain fish diving behavior in response to low magnitude $G$-force. (a) Normal level attitude in response to Earth gravity. Otolith weight bends sense hair by compression. (b) Diving response to low magnitude $G$-force. Sense hair is bent at root in manner similar to (a) by shearing force with lever arm. 
of force. It also appears questionable whether the individual receptor unit can distinguish between pressure and shearing.

The individual sense hair under pressure will probably be bent so that its shaft is tilted sideward into a position essentially the same as that caused by a shearing force (Figure 10). The near weightlessness vestibular response of man and fish may be caused by the substitution of a low magnitude predominately shearing force as a vestibular reference in place of a normal, predominately pressure force. The moment resulting from the product of the shearing force and the length of the sense hair tends to equate the angular deflection of the sense hair root to that produced by the higher magnitude pressure force alone. A similar view has recently been indicated by Howland (1972).

Fish continued to loop and did not show any measurable adaptation during $30 \mathrm{~s}$ of aircraft weightless flight. The inversion illusion in man was also of a long duration. Dzendolet (1971) explained this lack of adaptation by the indefinite maintenance of an initial otolith displacement due to the lack of any restoring force. This explanation presents the following difficulties:

(1) The inversion illusion, the looping response and the diving response of fish persist, even when a small gravitoinertial force in the $z$-axis or $x$-axis is still present.

(2) These responses persist in spite of the fact that fish and man spontaneously change their body or head position during the weightlessness parabola, thereby applying various linear accelerating forces on their statoliths.

(3) The time for returning from a stimulated condition to the equilibrium position, when the stimulus suddenly stops, was found to be extremely short for linear acceleration, on the order of $0.1 \mathrm{~s}$ (equal to the time indicated by Jongkees and Groen, 1946). These measurements of the indicator time were made with the background stimulation of the Earth's gravity, which could have acted as a restoring force. If Dzendolet (1971) were right, it would follow that in a head position in which the utricular epithelium is about horizontal, a deflection of the sense hairs by a horizontal linear acceleration on the ground would not be removed unless a negative linear acceleration is applied. This is not the case, as man never feels accelerated while at constant speed.

It appears more likely that the macula receptor epithelium is able to sense not only the initial changes of direction, but also the more permanent changes of the magnitude of pressure and shearing forces acting through the otoconial membrane on its supporting surface. It is well known in general receptor physiology that faster adapting receptor units are used for the perception of differential values, while slow or even nonadapting units serve as position receptors after more permanent changes. The continued inversion illusion of man and the looping response of fish during parabolic weightless flight can best be attributed to such slow or non-adapting receptors.

\section{Applications of the Gravity Reference Response to Aircraft Flight}

Aside from when the vestibular apparatus is confused by angular accelerations, the only times in aircraft flight when occupants are not affected by the gravity reference 
response are during straight, level, constant speed flight and low $G$-force flight (below 0.8 or $0.9 \mathrm{~g}$, without other cues, based on work with blinded fish, von Baumgarten, et al., 1972). Otherwise, the occupants of the aircraft are, or may be, continuously orienting vestibularly to an 'apparent gravity', as if this acceleratory stimulus were the Earth's gravity. The aircraft occupants are generally unaware of this orientation to an apparent horizontal rather than to the actual horizontal, as the apparent horizontal generally is closely aligned with the longitudinal-lateral $(x-y)$ plane (the floor or deck) of the aircraft. In a normal climb or dive, the aircraft assumes an attitude only slightly nose-up or nose-down, compared with the aircraft attitude in level flight. In the balanced turn, the aircraft banks and aligns its lateral ( $y$-axis) with the apparent horizontal. Thus the reorientation of aircraft occupants to a new apparent gravity is usually masked in normal balanced flight as the aircraft simultaneously closely aligns itself to this new reference.

In cases of unbalanced or abnormal flight, such as slipping or skidding, the gravity reference response presents a new vestibular orientation that causes discomfort to the aircraft occupants. So far as the aircraft operators are concerned, the gravity reference response in these cases is helpful as a reference for correcting unbalancing disturbances and maintaining the aircraft in balanced flight.

There are maneuvers or evolutions during which the gravity reference response can be deceptive, such as the rotation sensation described earlier above. These occur when the relative direction of the gravitoinertial acceleration loading is changed abruptly while the aircraft attitude does not change in a similar manner. If the aircraft is accelerated longitudinally, such as with the application of engine power, by the sudden reduction in aerodynamic drag, and/or by the cessation of ground contact in the takeoff roll, forward-facing occupants experience the sensation of being tilted back. On the other hand, if the aircraft is decelerated Iongitudinally, such as by the reduction of engine power, the application of aerodynamic braking, contact with the ground during the landing, or the application of mechanical brakes and/or engine reverse thrust, the forward-facing occupants experience the sensation of being tilted forward. Deceptive rotation sensations also occur during the pushover from a high $G$-force to attempted weightless flight and the pullout from attempted weightless flight to a high $G$-force if each of these maneuvers is performed without proper power modulation.

There are circumstances where the gravity reference response may cause dangerous consequences, as when the aircraft takeoff is assisted by rocket or catapult. During the assisted takeoff run, the aircraft occupants facing forward have the sensation of being tilted backward. Without benefit of other references, such as the actual horizon or flight instruments, the pilot may erroneously think that the aircraft is pitching upward toward a stall and he may attempt to correct this misinterpreted attitude with an abrupt dive or by assuming an erroneous level aircraft attitude, which result in a dive or loss of altitude at a critical time. This phenomenon might be responsible for some accidents during which an aircraft for unexplained reasons contacted the ground or water immediately after takeoff in limited visibility or at night, especially after being catapulted from an aircraft carrier. 


\section{Acknowledgment}

The jet aircraft services, the jet aircraft experiment installation and the photographic services aboard the jet aircraft were provided by Ames Research Center, NASA, Moffett Field, California.

\section{References}

Berry, C. A.: 1969, Aerospace Med. 39, 792-797.

Berry, C. A.: 1972, XXth Congress of Aviation and Space Medicine at Nice, France, September 18-21.

Billingham, J.: 1966, Proc. 2nd Symp. on the Role of the Vestibular Organs in Space Exploration, NASA SP-115, 5-13.

Carlile, J.: 1961, WADD Technical Report 60-715, Wright-Patterson Air Force Base, Ohio, pp. 5-8.

Clark, B.: 1968, Proc. 3rd Symp. on the Role of the Vestibular Organs in Space Exploration, NASA SP-152, 331-340.

Dzendolet, E.: 1971, Aerospace Med. 42, 1211-1213.

Garland, N. R.: 1961, WADD Technical Report 60-715, Wright-Patterson Air Force Base, Ohio, pp. 9-13.

Gerathewohl, S. J.: 1956, Astronautica Acta 2, 203-217.

Gerathewohl, S. J. and Stallings, H. D.: 1958, J. Aviat. Med. 29, 504-516.

Graybiel, A.: 1952, Arch. Ophthal. 48, 605-615.

Graybiel, A. and Kellogg, R. S.: 1966, Proc. 2nd Symp. on the Role of the Vestibular Organs in Space Exploration, NASA SP-115, 15-24.

Howland, H. C.: 1972, Personal communication to R. J. von Baumgarten.

Jongkees, L. B. W. and Groen, J. J.: 1946, J. Laryngol. Otol. 61, 529-540.

Jongkees, L. B. W.: 1950, Acta Oto-Laryngol. (Stockholm) 38, 18-26.

Jongkees, L. B. W.: 1968, Proc. 3rd Symp. on the Role of the Vestibular Organs in Space Exploration, NASA SP-152, 307-330.

Money, K. E.: 1970, Physiol. Revs. 50, 1-39.

Ogino, L., Yamagata, M., and Makio, H.: 1963, Yonugo Acta Med. 7, 139.

Rand, H. W.: 1950, The Chordates, The Blakiston Co., Philadelphia and Toronto.

Useller, I. W., Enders, I. H., and Haise, Jr., W.: 1965, NASA Technical Note TN D 3380.

Von Baumgarten, R. J., Atema, J., Hukuhara, T., and Rocker, M.: 1969, Space Life Sci. 1, 554-564.

Von Baumgarten, R. J., Baldrighi, G., Atema, J., and Shillinger, G. L., Jr.: 1971, Space Life Sci. 3, $25-33$.

Von Baumgarten, R. J., Baldrighi, G., and Shillinger, G. L., Jr.: 1972, Aerospace Med. 43, 626-632.

Von Baumgarten, R. J., Thümler, R., Shillinger, G. L., Jr., and Baldrighi, G.: 1973, 'Human Eye Movements During Various Forms of Linear Acceleration and Weightlessness', AGARD Meeting, The Use of Nystagmography in Aviation Medicine, Pensacola, Florida. Conference proceedings in press.

Von Békésy, G.: 1966, Arch. Otolaryngol. 84, 122-130.

Weiss, R.: 1962, Zero-Gravity Parabola Techniques, Lear, Inc., Grand Rapids, Michigan.

Yamagata, M.: 1958, J. Oto-Rhino-Laryngol. Soc. Suppl. 61, 1631. 